\title{
Making Connections With Case Studies: A Student's Perspective
}

\author{
Yaxin Zheng \\ Electrical Engineering, University of Waterloo \\ y45zheng@uwaterloo.ca
}

\begin{abstract}
Post-secondary engineering students have difficulty with course concepts due to disconnect between theory and practice. Due to its co-op program, University of Waterloo students are at a unique position of being able to put course knowledge into practice shortly after classroom exposure. Through the hands-on experience gained from co-op, students are able to better understand course concepts. Case studies serve to replicate the practical context provided by co-op and work, giving students an opportunity to see the real-life utilization of the concepts learned from lectures. Our exposure to cases in class greatly increased understanding of course concepts among my peers. Cases helped us realize the real-life relevance of the theories learned in class, confusing information taught in class. As a case writer, I saw the painstaking effort put into case development, to ensure maximum effectiveness. Due to its ability to provide practical application of knowledge within a short amount of time, cases are an extremely valuable educational tool for engineering students.
\end{abstract}

Keywords: education; cases; teaching; engineering; case study method

\section{INTRODUCTION}

For many students in North America, the transition to post-secondary education is not easy. The breadth and scope of course concepts can be very challenging, leading students to feel overwhelmed. This is especially true for engineering students, who are exposed to numerous subjects that seem to have little connection between each other, and only little relevance to what they wish to achieve. Some students may even find their courses "boring" or "unnecessary", quickly memorizing large amounts of information for tests, and then promptly forgetting much of the concepts memorized. The reverse occurs upon entrance into the working world. Students suddenly find that the once "irrelevant" knowledge taught in class is extremely applicable to their duties at work. As well, the material from their seemingly disconnected courses suddenly ties together.
Students often feel overwhelmed by the increased difficulty of course concepts, which seem irrelevant to their career interests. It is often upon entrance into the working world that they are able to make the connection between theory and practice. Furthermore, students that do not have prior experience in industry may be illprepared and lacking critical interpersonal skills to be efficient workers [1].

Due to the coop program at the University of Waterloo (UW), this realization hits UW students sooner than those attending most other institutions. Although every course has a relevant real-world application, not every student has an opportunity to experience a relevant coop placement for every course. Case studies are effective in remedying this disconnects, by bringing practical applications of materials into the classroom. Through case studies, students are able to apply course concepts to practical contexts, and take education beyond the confines of the classroom walls.

Many will refer back to their old lecture notes, and even beyond, now learning not to pass an evaluation, but for the purpose of understanding. Students only realize the importance of their courses when they are required to call upon them in the working world. Like many of my classmates, I have stumbled through course concepts during lectures, minimally comprehending them and finding them irrelevant to the real world. However, it was only when I experienced working in industry (through coop placements) that I realized the importance of what I was taught in class. I only wished that I could have such relevant practical experience for every course that I was taught. Although lectures provided a necessary theory background, the inflexible assignments and structured labs did not allow room for creativity or problem solving, poorly preparing university students for working in industry. Without practical contexts to connect theory with the real world, the concepts taught in lectures seemed of little importance to students unless they were able to find a coop placement in a relevant field. Most engineering students enter the program due to having a hands-on learning style; the traditional lecture-based teaching method does not benefit engineering students if not used in conjunction with elements that allow them to connect it with a relevant real-life problem. 


\section{LEARNING IN THE CLASSROOM}

\subsection{Transitioning to University}

"The freshman 15" is a common phrase used to describe the 15-30 pound weight gain experienced by first year university students, who develop poor eating habits in the absence of parental guidance. For engineering students, this pertains to two phenomena: the aforementioned increase of girth, and the decrease in grade average due to poor study habits and difficulty adjusting to university.

Many university students majoring in engineering were at the top of their class in high school: a proverbial "big fish in a small pond." For many, they had never experienced academic struggle or failures until entering university. The transition out of their parents' homes, to a life of semi-independence and self-reliance, is already emotionally difficult for students. For engineering students, they must deal with both the emotional difficulty of independence, as well as academic difficulties that are exponentially higher than concepts learned during high school.

Engineering programs have a well-deserved reputation of being "difficult," picking its students from among the brightest, most academically successful applicants. However, due to having strict standards stemming from a solid history of academic success, first year engineering students are unprepared for dealing with difficulty and failure. Even I fell victim; although I had been told that my average would drastically decrease upon entering university, I found this incomprehensible, as I regularly scored $90 \%$ and above on tests and projects, and I even considered $80 \%$ a "poor mark". However, harsh reality hit my classmates and I when we completed our first set of university midterms. For many of us, the marks we received were much lower than anything we had ever achieved before, and we shamefully recounted the nostalgia of the days when we had considered $80 \%$ "poor." Some accepted their failure, and strived to work harder, while others were unable to come to terms with the fact that their performance did not meet their own high standards, and gave up completely. Unfortunately, some of us were unable to pull our performance together in time to achieve a sufficient grade to advance into the next semester. After the first semester, a significant $10 \%$ to $30 \%$ of our classmates failed or transferred to other programs. The faces around us continuously changed during the next few semesters, as students continued to fail or transfer, and upper year students that were required to repeat a semester joined our class.
By fourth year, university students seem to develop sufficient study habits such that failure is no longer likely. Their academic performance is also more reflective of the high marks achieved during high school. However, the evolution of these study skills seems almost fruitless when they are soon to enter a world that no longer emphasizes such skills. Very few engineering majors choose to pursue graduate degrees; most enter industry and begin working after graduation [4]. Although some universities - most notably, the University of Waterloo and University of Toronto - offer undergraduate students the opportunity to gain industry experience through coops and internships, job-seeking university students enter the working world without any relevant experience. Although these young workers may have sufficient technical background from their degrees, they are doomed to repeating the transition difficulties from high school to university if they are not given sufficient industry exposure prior to graduation.

\subsection{Entering the Working World}

Employers of engineering graduates must often deal with their new employees' lack of analytical and critical thinking skills. Additionally, they complain that their new hires show poor communication and teamwork, and do not have adequate understanding of engineering and business practice [1]. In short, engineering graduates, despite being knowledgeable academics, lack ability to function in the real world. This is a product of traditional lecture-based instruction, which research has shown to be ineffective for development of high-level skill development [1].

The heavy workload given to engineering students necessitates that their lives revolve around academia. In my third school term at UW (first semester of second year), my classmates and I were taking six courses, five of which included a lab component. For many students, this means that any semblance of a social life is destroyed, as they become submerged in an "engineering world" filled with course concepts and other engineering students. With emphasis placed on exam performance and assignment completion, engineering students are trained to value technical skills above interpersonal skills. I have observed this among my peers, some of which are brilliant scholars, but lack soft skills, and the willingness to develop them. This one-track, inflexible type of thinking is detrimental in the workplace.

For busy engineering students, a life immersed in study is unavoidable. It is apparent that the traditional lecture-based method of education is not effective in producing well-rounded engineering graduates, who will one day be thrown into the world of employment. For 
many of us, this move will be as harsh and abrupt as the transition from high school to university. While it may not be possible for students to mentally and emotionally leave the closed walls of academia during their time in school, it is possible to bring the real world to them. It is clear that educators must steer away from purely lecture-based teaching, in order for students to develop both the technical and soft skills needed to function in the real world.

Academic experiences in university poses a challenge to most engineering students. For majority of the students, the course topics and lecture concepts are very difficult. These students mainly have a problem comprehending the challenging concepts because they are unable to make a connection between the seemingly arbitrary information with important real-life problems. Many of these students resort to rote memorization before tests with in an effort to salvage their marks. This is harmful, as rote memorization does not contribute to their active understanding of course concepts. Just as relying on rote memorization impairs vocabulary development when used for language studies [2], relying on rote memorization in engineering encourages students to parrot answers instead of understanding the theory behind these answers. Rote memorization has very little value in the work environment, and employees raised on rote memorization instead of concept comprehension are undesirable in industry. For these students, hands-on learning and connecting the seemingly arbitrary course material with real life applications is greatly helpful in enriching comprehension.

On the other end of the spectrum, some students find the structured, lecture-based engineering courses extremely easy. However, their affinity for such structured courses are also unhelpful in preparing them for industry, as problems in the real world are not like the neatly packaged courses that they excel at. Industry problems require content from various areas, and even multiple disciplines (including non-engineering concepts such as finances and human resources) to develop satisfying solutions. Unlike assignment problems offered in courses, real-life problems never occur in a perfectly controlled environment, and are open to effects from outside interaction. Attempting to contain problems within one discipline is unrealistic in practical contexts, and the structured, lecture-based engineering courses that most engineering disciplines offer, while helpful in training students in theory, detrimentally encourages "in the box" thinking in students. Therefore, it is becoming abundantly clear that structured, lecture-based courses are not beneficial for training effective engineers for the real world. Undergraduates would benefit greatly from exposure to real-world engineering situations, and practice in applying theory to practical contexts.

CEEA14; Paper 41

Canmore, AB; June 8-11, 2014

Page 3 of 6

\section{CASE STUDIES}

The case study method of teaching is an educational approach that allows students to apply course concepts to relevant practical situations. Case studies are typically developed with reference to real-life scenarios, and due to this basis in reality, introduces factors that are often unaccounted for in the perfect "vacuum" settings used for problem solving in traditional lecture-based instruction. Case studies are meant to complement the material taught in lectures and classrooms by offering students an opportunity to demonstrate the application of classroom knowledge to practical contexts. Case studies reinforce the material that is taught in class, increasing student understanding and retention.

Waterloo Cases in Design Engineering (WCDE) writes cases from co-op work term reports. Students and student resources are an integral part of WCDE's activities; almost all of WCDE's case studies are developed from student work term resorts, project papers, and other relevant documents. As these documents reflect on their authors' progress of learning and development, they are useful in demonstrating concepts to the authors' peers, who possess a similar level of knowledge. Apart from student work term reports, WCDE also employs co-op students for the development of case studies and promotion of WCDE activities. The co-op student is usually a senior year student majoring in engineering at the University of Waterloo; this provides them with the necessary background to knowledgeably create cases, while maintaining sympathy and understanding for their target audience. Co-op students have experienced a case study in their own courses, and can bring their own insights to case study writing.

\section{MAKING CONNECTIONS}

Case studies are significantly utilized in fields such as business, law, and psychology, used to "obtain a detailed description" and "yield a great deal of information" on a specific topic. Although the field of psychology considers case studies to be of great importance, professors in the field do not primarily depend on them in teaching, due to the fact that case studies limits study to a specific situation [3]. Instead, in psychology, case studies are used in conjunction with lecture-based teaching and theory, to aid in comprehension of theory and enrich the student's learning experience with examples of real-life application. From personal experience, I have found that peers taking psychology electives have maintained higher 
interest and excitement for their courses than my engineering classmates, citing case studies as a major reason for their enthusiasm. Therefore, engineering courses similarly benefit from the inclusion of case studies, which serve to "[humanize] data that might otherwise appear dry and lifeless," [3] and allow students to see the topics presented in their courses as real problems involving engineers and engineering ethics, instead of mere numbers and equations.

As mentioned previously, most of my classmates found our courses challenging because they were unable to find a connection between the numbers, equations, and technical terms in assignments and readings, and the reallife, hands-on engineering problems that attracted them to the field in the first place. Assignments were rigid with little room for creativity, and textbook readings were often so long and dull that students either memorized seemingly important passages without context, or completely forwent assigned readings. Although labs helped in providing us with some hands-on experience and valuable time with equipment, they also occur in a closed environment. Labs and projects typically followed one "correct" path to a "correct" answer, providing little room for interpretation. For us, the most helpful method was seeking professors and teaching assistants (TA) for one-on-one sessions to discuss course concepts; however, the teaching staff was completely outnumbered by students (especially in lower years, when all students took the same courses), and would not have had time to schedule one-on-one sessions with all students.

UW students are fortunate to be able to participate in its famed coop program, where they are able to experience the real world as a contributing member to a company in industry or academia. Students are then given the opportunity to apply the concepts they had previously learned in class to their duties at work. Through coop placements, many of my classmates became very proficient at concepts that they only adequately understood from lectures and assignments only; the hands-on experience from coop combined with the theoretical background from class to give students solid mastery of certain areas. In the real world, the solutions for problems are not neatly packaged like in assignments and labs. Although students were provided with a sufficiently rich and wide variety of foundation courses, only real-life experience putting theory into practice allowed the students to solidify their proficiency with the information gleaned from these courses.

Unfortunately, it is not possible to provide students with a coop placement relevant to every course they learn. CEEA14; Paper 41

Canmore, AB; June 8-11, 2014

Page 4 of 6
However, engineering case studies remedy this problem, by giving students a simulation of the real-world, multidiscipline, open-ended problems they may encounter in industry. In addition to being able to experience real-life engineering problem solving hands-on, students must also conduct extra research and delve into sources outside of the information handed to them via lecture notes. Just like working in industry, case studies require students to be resourceful and creative. Case studies contain group work components that train students to work in teams and develop invaluable interpersonal and teamwork skills that are a necessity for industry. Discussion is helpful for students that are auditory learners, and enriches each individual by allowing them to benefit from the wisdom of the collective, resulting in much better formation of solutions than the straightforward, step-by-step problem solving provided by assignments.

\section{DISCUSSION}

The effectiveness of case studies can be shown by the results of its integration in engineering courses. Before my employment with WCDE, I had experienced several courses that incorporated the use of case studies. The most poignant experience comes from its inclusion as a part of ECE 224: Embedded Microprocessor Systems, a mandatory course that was infamously difficult and timeconsuming. Prior to my enrollment in the course, I had observed another class that contained several of my friends take the course. Due to the challenging concepts and lengthy, difficult assignments, the class's midterm average was in the mid-30s. The final course average was also poor, and a significant portion of the students - many of which are outstanding students in other courses - did not pass the course. A case study, "Nuvation - Design of Power Supply" was included during my class's time in the course. In this case study, our class was assigned to select a universal asynchronous receiver/transmitter (UART) for Texas Instruments, thus providing an opportunity to investigate and become familiar with RS-232, USBs, and other significant topics in the course. As a result, everyone in my class achieved a passing grade. Although my class's more successful performance cannot be purely attributed to the inclusion of the case study, it undeniably aided us in the comprehension of course topics.

In addition to experiencing case studies as a student, my time with WCDE allowed me to see case studies from the perspective of a case writer. If completing case studies had helped my understanding of engineering concepts, writing case studies was even more constructive to my 
development as a well-rounded future engineer. Writing full case studies required consideration of factors other than technical problem solving; like in the real world, topics such as ethics and economics were also required when developing case studies. My WCDE coworkers and I frequently edited and proofread each other's work, and met weekly to discuss case development, all to ensure that the highest quality of cases were being met. Developing case studies from work term reports ingeniously utilizes UW's coop culture, which provides a supply of readymade summaries of real-world engineering problems in the form of work term reports. Although I did not have the background as the authors of these work term reports, the content of the work term reports provided succinct summaries that were easily translated into material for case studies. Authors of the case studies also enrich technical knowledge and sharpen their problem-solving skills.

Engineering undergraduates in North American no longer seek graduate school immediately after graduation, if at all. Geils reported that in the United States, 23.5\% less doctoral degrees were awarded in engineering in 1982 and 1972, and the mentality that graduate school is unnecessary continues to persist among engineering undergraduates [4]. Thus, Universities must now focus on making their graduates employable, and to develop curriculums with such appropriate emphasis on the "transference of appropriate skills and attributes" for graduates to "succeed in the industry." Newton and Delatte found case-based teaching as an effective form of inductive learning for civil engineering, to quickly develop skills that employers expect new graduates to have before hiring them. Furthermore, case studies have been praised in literature as a desirable student-centered approach to teaching [5][3]. Engineering students wish to pursue working in industry "passing up graduate school" for the glamour and "high salaries of industry" [4]. Most of my classmates dream of working for industry giants such as Apple, Facebook, and Microsoft. Due to Waterloo's advantageous location, there are even many large corporations located locally, such as Christie Digital, Linamar, and Amec. WCDE's collaboration with industry professionals, including the aforementioned local corporations, is extremely valuable in providing a link between students and employment. WCDE's industry partners, who are extremely interested in developing skilled, well-rounded students that are potentially valuable additions to their respective corporations, are helpful in aiding WCDE in the development of efficient teaching tools to prepare students for working in industry. As technology becomes increasingly advanced, Felder predicts that traditional engineering jobs will be outsourced to "either computers or engineers in countries with low labour costs." [1] If that is the case, it is now more important than ever for universities to develop future engineers with important interpersonal, critical thinking, and problem solving skills. Future engineers must therefore possess the humanizing skills that cannot be performed by a computer, and cannot be trained by straightforward, closed-ended, structured lectures and assignments.

\section{CONCLUSION}

This paper explored the challenges experienced by engineering students, with respect to challenges encountered by freshmen in the transition from high school to university. It was noted that students found difficulty with courses because they found course concepts to be irrelevant to their interests, and could not make the connection between lectures and the real world. Additionally, employers have found engineering students to lack in problem-solving and interpersonal skills, setting current university graduates to repeat their high school-touniversity transition difficulties when they progress to the working world. Tests, assignments, and labs are often too straightforward to develop sufficient problem-solving skills in students. Case studies provide the experience of a real-life engineering problem in a relatively short amount of time, giving students opportunities to solve open-ended problems, drawing knowledge from multiple courses and applying course concepts to practical contexts. Case studies, and university groups promoting their use, such as WCDE, work with industry professionals and professors to serve as a link between students and employment. Case studies are a valuable tool that works alongside traditional lecture-based teaching, to enrich student understanding and enjoyment of engineering courses.

\section{Acknowledgements}

I would like to acknowledge Professor Steve Lambert, David Effa, Cheryl Pearce, and other members of the Waterloo Cases in Design Engineering group for their assistance in the completion of this conference paper.

\section{References}

[1] Richard M. Felder, Engineering Education: A Tale of Two Paradigms. North Carolina University, 1-10, pp. Available as of March 17, 2013 from http://www4.ncsu.edu/unity/lockers/users/f/felder/publ ic/Papers/TwoParadigms.pdf 
Proc. 2014 Canadian Engineering Education Association (CEEA14) Conf.

[2] Weidong Yang and Weiping Dai, "Rote Memorization of Vocabulary and Vocabulary Development," English Language Teaching, vol. 4, no. 4, pp. 61-64, 2011.

[3] David H. Barlow, V. Mark Durand, and Sherry H. Stewart, Abnormal Psychology: An Integrative Approach. Toronto, ON: Nelson Education Ltd., 2012 (3rd ed.), xxi, 108 pp. \{ISBN: 978-0-17-650219\}

[4] Jon. W. Geils, "Why students reject engineering teaching careers," Communications of the ACM, vol. 27, no. 1, pp.25-27, 1984.

[5] Timothy A. Newson and Norbert J. Delatte, "Case methods in civil engineering teaching," Can. J. Civ. Eng., vol. 38, pp. 1016-1030, 2011. 